ISSN = 1980-993X - doi:10.4136/1980-993X
www.ambi-agua.net
E-mail: ambi-agua@agro.unitau.br
Tel.: (12) 3625-4212

\title{
Atributos microbianos do solo fertilizado com composto de lodo de esgoto
}

(http://dx.doi.org/10.4136/ambi-agua.915)

\section{Ericléia Büerg Suszek¹; Paulo Fortes Neto ${ }^{1}$; Nara Lúcia Perondi Fortes ${ }^{1}$; Eliana Maria de Araújo Mariano da Silva ${ }^{1}$; Fabiana Brambatti ${ }^{1}$; Claudio Roberto Silva ${ }^{2}$; Dimas Donizeti Patrocinio ${ }^{2}$}

\author{
1Universidade de Taubaté, Departamento de Ciências Agrárias, Taubaté, SP \\ e-mails: ericleiaagro@yahoo.com.br,paulofortes.neto@gmail.com,nara_fortes@uol.com.br, \\ emams.master@gmail.com, fabi_bram@hotmail.com \\ ${ }^{2}$ Fibria Celulose S/A. email: claudio.silva@ fibria.com.br, dimas.patrocinio@fibria.com.br
}

\section{RESUMO}

A aplicação do composto de lodo de esgoto em áreas agrícolas pode promover alterações nos atributos microbianos do solo. Assim, há necessidade de se avaliar o impacto da adição do composto sobre a atividade microbiana do solo. O presente trabalho objetivou avaliar a alteração nos atributos microbianos de um solo fertilizado com diferentes doses de composto de lodo por meio da medida de liberação de $\mathrm{CO}_{2}$ e a contagem de bactérias e fungos. $\mathrm{O}$ experimento foi realizado em condição de laboratório, com jarros respirométricos contendo em seu interior amostras de solo misturadas com composto nas doses de $0 ; 20 ; 40 ; 60$ e $80 \mathrm{Mg}$ ha ${ }^{-1}$. A liberação de $\mathrm{CO}_{2}$ do solo foi medida diariamente durante os 28 dias de incubação. Após a incubação, as amostras de solo foram retiradas dos jarros e submetidas à contagem de bactérias e fungos e à determinação da composição química do solo. Os tratamentos correspondentes às doses do composto foram dispostos em delineamento completamente casualizado com quatro repetições. A liberação de $\mathrm{CO}_{2}$ e o número de bactérias e fungos aumentaram significativamente com as doses do composto devido ao fornecimento de substrato energético e nutrientes proporcionados pelo composto. A medida de liberação de $\mathrm{CO}_{2}$ indicou que a doses de composto acima de $20 \mathrm{Mg} \mathrm{ha}^{-1}$ ocasionou impactos significativos sobre a atividade microbiana do solo.

Palavras-chave: atividade microbiana, bactérias, fungos.

\section{Soil microbial attributes treated with composting of sewage sludge}

\section{ABSTRACT}

The use of sludge composting in agricultural areas alters the microbial functions. In this context it is necessary to evaluate the impact of composting addition on microbial activities in the soil. This study evaluated the alteration of microbial attributes of a soil fertilized with sewage sludge compost by measuring the $\mathrm{CO}_{2}$ release rates and counting bacteria and fungi numbers. This experiment was conducted in laboratory using respirometric jars that contained samples of soil mixed with different doses of compost: $0 ; 20 ; 40 ; 60$ and $80 \mathrm{Mg} \mathrm{ha}^{-1}$, and $\mathrm{CO}_{2}$ release was quantified daily during the 28 days of incubation when the samples were removed from the jars and bacteria and fungi quantities were counted. The treatments corresponding to each dose of the composting were arranged in completely randomized design with four replications. The $\mathrm{CO}_{2}$ release and the quantity of bacteria and fungi increased with additional doses of the compound. This occurred as a result of supplying energetic substrate and 
SUSZEK, E. B.; FORTES NETO, P.; FORTES, N. L. P.; SILVA, E. M. A. M.; BRAMBATTI, F.; SILVA, C. R; PATROCINIO, D. D. Atributos microbianos do solo fertilizado com composto de lodo de esgoto Ambi-Agua, Taubaté, v. 7, n. 2, p. 49-61, 2012. (http://dx.doi.org/10.4136/ambi-agua.915).

nutrients from the compound. The $\mathrm{CO}_{2}$ released measurements indicated that compound above $20 \mathrm{Mg} \mathrm{ha}^{-1}$ has significant impact on soil microbial activity.

Keywords: microbial activity, bacterial, fungi.

\section{INTRODUÇÃO}

Os microrganismos possuem uma capacidade de dar respostas rápidas a mudanças nos atributos microbianos do solo, isto ocorre porque, as reações biológicas e bioquímicas são catalizadas pelos microrganismos (Brookes, 1995; Vieira et al., 2011). Essas reações são responsáveis pela decomposição de resíduos orgânicos, pela ciclagem biogeoquímica, incluindo a fixação de $\mathrm{N}_{2}$, pela formação de agregados do solo e pela taxa de decomposição de materiais orgânicos (Elsas et al., 1997). Devido a essas características, os microrganismos do solo são considerados como indicadores sensíveis para avaliar o impacto antropogênico sobre os processos biológicos do solo (Dick, 1994; Doran e Parkinson, 1994; Turco et al., 1994).

Os estudos referentes ao uso de medidas microbiológicas como indicadoras de poluição do solo e do ambiente têm sido desenvolvidos com o objetivo de verificar a ação dos elementos contaminantes, provenientes de fertilizantes, pesticidas, resíduos orgânicos e do manejo do solo, sobre a comunidade e a atividade microbiana do solo (Fortes Neto, 2000; Bettiol e Fernandes, 2004; Gil-Sotres et al., 2005; Sullivan et al., 2006; Vieira et al., 2011).

A utilização de medidas microbiológicas para indicar a qualidade do solo vem sendo pesquisada porque os microrganismos mantêm uma íntima relação com as propriedades químicas e físicas do solo e, também, porque são responsáveis por inúmeros processos biológicos e bioquímicos do solo; por isso, são sensíveis às alterações de origens naturais e antropogênicas que ocorrem nele. Entretanto, apesar dessa característica dos microrganismos, há vários critérios básicos para que uma propriedade microbiana possa ser considerada como indicadora ideal para avaliar as alterações resultantes do manejo dado ao solo (Brookes, 1995; Marchiori Júnior e Melo, 1999; Trasar-Cepeda et al., 2000; Silva et al. 2007; Santos et al., 2011).

De acordo com Brookes (1995), a propriedade microbiana deve apresentar as seguintes características: (1) ser mensurável de forma acurada; (2) ser testada em uma variedade de tipos e condições de solo; (3) ser sensível à ação do agente em estudo; e (4) apresentar validade científica confiável.

As propriedades microbianas sensíveis às variações provocadas no solo pelos elementos poluidores são divididas em três grupos. O primeiro é aquele que mede a atividade microbiana global; o segundo determina o tamanho da população de um organismo, de um grupo funcional, ou da comunidade; e o terceiro é a correlação da atividade com a comunidade microbiana predominante no solo (Brookes, 1995).

As análises microbiológicas são úteis na avaliação da qualidade do solo; porém, vários autores relataram a necessidade de se utilizarem diversas análises ao mesmo tempo, para se ter uma noção mais precisa das interferências ocasionadas pelos agentes poluentes no solo. (Turco et al., 1994; Brookes, 1995; Jahnel et al., 1999; Lisboa et al., 2012).

Nos estudos para determinar os efeitos dos agentes contaminantes e do manejo do solo sobre as atividades e a dinâmica das comunidades microbianas, as análises mais utilizadas como indicadoras são: liberação de $\mathrm{CO}_{2}$ pela respiração microbiana; mineralização de nitrogênio e carbono; fixação biológica de nitrogênio; atividades enzimáticas; contagem de grupos microbianos e biomassa microbiana de C, N, P e S (Marchiori Júnior e Melo, 1999; Paula et al., 2010; Zhong et al., 2010). 
Estudos integrados dessas atividades microbianas poderão fornecer dados importantes para a elaboração de índices de qualidade biológica de solos, necessárias para diagnosticar e monitorar impactos ambientais sobre a microbiota do solo (Turco et al., 1994; Brookes, 1995; Banerjee et al., 1997; Roscoe et al., 2006).

Com base no exposto, o presente trabalho teve como objetivo avaliar a alteração nos atributos microbianos do solo fertilizado com composto de lodo de esgoto, por meio de medidas microbiológicas de liberação de $\mathrm{CO}_{2}$ e de contagem de bactérias e fungos.

\section{MATERIAIS E MÉTODO}

No presente estudo foi utilizada amostra de um Latossolo Vermelho Amarelo distrófico (Embrapa, 1999) coletada na camada de $0-20 \mathrm{~cm}$ de profundidade em uma área de plantio comercial de eucalipto localizada no município de Guararema/SP. O solo apresentou as seguintes características químicas: $\mathrm{pH}\left(\mathrm{CaCl}_{2}\right)=4,0$; matéria orgânica $=23,6 \mathrm{~g} \mathrm{dm}^{-3}$; $\mathrm{P}=3,0 \mathrm{mg} \mathrm{dm} ; \mathrm{K}=0,4 \mathrm{mmol}_{\mathrm{c}} \mathrm{dm}^{-3} ; \mathrm{Ca}=2,0 \mathrm{mmol}_{\mathrm{c}} \mathrm{dm}^{-3} ; \mathrm{Mg}=1,0 \mathrm{mmol}_{\mathrm{c}} \mathrm{dm}^{-3}$; $\mathrm{Al}=14,3 \mathrm{mmol}_{\mathrm{c}} \mathrm{dm}^{-3} ; \mathrm{SB}=4,0 \mathrm{mmol}_{\mathrm{c}} \mathrm{dm}^{-3} ; \mathrm{T}=95,2 \mathrm{mmol}_{\mathrm{c}} \mathrm{dm}^{-3} \mathrm{e} \mathrm{V}=3 \%$.

O composto utilizado foi produzido a partir da mistura de lodo de esgoto com cavaco de madeira e cinza de caldeira gerada pela produção de celulose na unidade Fabril da empresa FIBRIA Celulose S/A, situada em Jacareí/SP. Os resíduos foram compostados durante um período de 120 dias, e a sua composição química e biológica, conforme especificada pela Resolução CONAMA n ${ }^{\circ} 375$ de 2006 (Brasil, 2006), está apresentada na Tabela 1.

Tabela 1. Características químicas e biológicas do composto resultante da mistura de lodo de esgoto com cavaco de madeira e cinza de caldeira.

\begin{tabular}{|c|c|}
\hline Atributo $^{(1)}$ & Valor $^{(2)}$ \\
\hline $\mathrm{pH}$ & 6,5 \\
\hline Nitrogênio total $\left(\mathrm{g} \mathrm{kg}^{-1}\right)$ & 3,0 \\
\hline Carbono orgânico $\left(\mathrm{g} \mathrm{kg}^{-1}\right)$ & 88,0 \\
\hline Relação C/N & $29 / 1$ \\
\hline Cálcio $\left(\mathrm{g} \mathrm{kg}^{-1}\right)$ & 100 \\
\hline Sódio $\left(\mathrm{g} \mathrm{kg}^{-1}\right)$ & 4,8 \\
\hline Magnésio $\left(\mathrm{g} \mathrm{kg}^{-1}\right)$ & 8,3 \\
\hline Potássio $\left(\mathrm{g} \mathrm{kg}^{-1}\right)$ & 5,0 \\
\hline Fósforo $\left(\mathrm{g} \mathrm{kg}^{-1}\right)$ & 2,2 \\
\hline Arsênio $\left(\mathrm{mg} \mathrm{kg}^{-1}\right)$ & $<0,5$ \\
\hline Bário $\left(\mathrm{mg} \mathrm{kg}^{-1}\right)$ & 230 \\
\hline Cádmio $\left(\mathrm{mg} \mathrm{kg}^{-1}\right)$ & $<0,5$ \\
\hline Chumbo $\left(\mathrm{mg} \mathrm{kg}^{-1}\right)$ & 15 \\
\hline Cobre $\left(\mathrm{mg} \mathrm{kg}^{-1}\right)$ & 33 \\
\hline Cromo $\left(\mathrm{mg} \mathrm{kg}^{-1}\right)$ & 10,6 \\
\hline Mercúrio $\left(\mathrm{mg} \mathrm{kg}^{-1}\right)$ & $<0,03$ \\
\hline Molibdênio $\left(\mathrm{mg} \mathrm{kg}^{-1}\right)$ & $<0,5$ \\
\hline Níquel $\left(\mathrm{mg} \mathrm{kg}^{-1}\right)$ & 1,9 \\
\hline Selênio $\left(\mathrm{mg} \mathrm{kg}^{-1}\right)$ & $<0,5$ \\
\hline Zinco $\left(\mathrm{mg} \mathrm{kg}^{-1}\right)$ & 12 \\
\hline Coliformes termotolerantes $\left(\mathrm{NMPg}^{-1}\right.$ de ST) & $<1,8$ \\
\hline Ovos viáveis de helmintos (ovos $\mathrm{g}^{-1}$ de $\mathrm{ST}$ ) & 0,0 \\
\hline Salmonella spp (10 g de ST) & Ausente \\
\hline
\end{tabular}


SUSZEK, E. B.; FORTES NETO, P.; FORTES, N. L. P.; SILVA, E. M. A. M.; BRAMBATTI, F.; SILVA, C. R; PATROCINIO, D. D. Atributos microbianos do solo fertilizado com composto de lodo de esgoto Ambi-Agua, Taubaté, v. 7, n. 2, p. 49-61, 2012. (http://dx.doi.org/10.4136/ambi-agua.915).

O cálculo para definir a dosagem (DR) foi realizado tendo como base a concentração do nitrogênio no composto e a quantidade $\left(120 \mathrm{~kg} \mathrm{ha}^{-1}\right)$ de nitrogênio recomendada para a cultura do eucalipto, conforme a equação abaixo descrita por Ilhenfeld e Andreoli (1999).

$$
\mathrm{DR}\left(\mathrm{Mg} \mathrm{ha}^{-1}\right)=\text { recomendação de } \mathrm{N} \text { para o eucalipto } \div \text { concentração de } \mathrm{N}(\%) \text { x } 5
$$

Com base na dose recomendada de composto $\left(80 \mathrm{Mg} \mathrm{ha}^{-1}\right)$, efetuou-se o delineamento experimental em blocos casualizados com cinco tratamentos e quatro repetições. Os tratamentos foram distribuídos em cinco doses de composto (base seca): $\mathrm{T}_{1}=0 \mathrm{Mg} \mathrm{ha}^{-1}$; $\mathrm{T}_{2}=20 \mathrm{Mg} \mathrm{ha}^{-1} ; \mathrm{T} 3=40 \mathrm{Mg} \mathrm{ha}^{-1} ; \mathrm{T}_{4}=60 \mathrm{Mg} \mathrm{ha}^{-1} \mathrm{e} \mathrm{T}_{5}=80 \mathrm{Mg} \mathrm{ha}^{-1}$.

O composto, nas dosagens correspondentes aos tratamentos, foi misturado a 50 gramas de solo com teor de água ajustado para $80 \%$ da capacidade de campo e, depois, colocado dentro de um jarro de vidro ( $1,5 \mathrm{~L})$ fechado hermeticamente, contendo, em seu interior, um cadinho de vidro com $10 \mathrm{~mL}$ de $\mathrm{NaOH}\left(0,5 \mathrm{~mol}_{\mathrm{c}} \mathrm{L}^{-1}\right)$.

Os jarros de vidro, depois de fechados, foram levados para a incubação em uma sala climatizada à temperatura de $28^{\circ} \mathrm{C} \pm 2$, por um período de sete dias. Em intervalos de dois dias, foram realizadas as determinações do $\mathrm{CO}_{2}$ desprendido pelas amostras de solo que foi capturado pelo hidróxido de sódio contido nos cadinhos de vidro. Aos cadinhos, contendo o hidróxido de sódio, foram adicionados $1 \mathrm{~mL}$ de $\mathrm{BaCl}_{2}(50 \%)$ e três gotas do indicador fenolftaleína $(3 \%)$ e, depois, foi efetuada a titulação com $\mathrm{HCl}\left(0,5 \mathrm{~mol}_{\mathrm{c}} \mathrm{L}^{-1}\right)$, para quantificação da massa liberada de $\mathrm{CO}_{2}$ por amostra de solo $\left(\mathrm{mg} \mathrm{g}^{-1}\right)$, conforme a metodologia descrita por Stotzky (1965). O valor médio de $\mathrm{CO}_{2}$ liberado do solo em cada período de coleta foi o resultado do somatório da quantidade de $\mathrm{CO}_{2}$ determinado durante 28 dias de incubação das amostras de solo.

As amostras de solo para determinar a composição química e a quantificação de bactérias e fungos foram retiradas dos jarros de vidro 28 dias após a incorporação das doses do composto.

A contagem de bactérias e fungos no solo foi determinada 28 dias após a aplicação do composto, e o método utilizado foi o de Número Mais Provável (NMP) de microrganismos do solo, a técnica utilizada foi a de plaqueamento em gotas de meio de cultura agarizado sobre placa de Petri (Jahnel et al., 1999).

As diluições para determinar a contagem de bactérias e fungos foram realizadas em uma suspensão obtida a partir de $10 \mathrm{~g}$ de solo suspenso em $90 \mathrm{~mL}$ de solução salina a $0,85 \%$, contidas em frascos Erlenmeyer. Os frascos foram submetidos, por 10 minutos, à agitação circulante e, depois, realizou-se as diluições sucessivas até $10^{-2}$ para fungos e até $10^{-3}$ para bactérias. Essas diluições foram realizadas transferindo-se, com o auxílio de uma micropipeta, alíquotas de $0,1 \mathrm{~mL}$ dos tubos de ensaio contendo $0,9 \mathrm{~mL}$ de água esterilizada.

O plaqueamento do meio de cultura agarizado foi realizado em câmara de fluxo laminar, com a distribuição de gotas com volume de $0,04 \mathrm{~mL}$ na superfície de placas de Petri esterilizadas. As placas foram vedadas e incubadas em estufa para D.B.O (demanda bioquímica de oxigênio), sob temperatura de $28^{\circ} \mathrm{C} \pm 2$, por um período de 48 horas. Após o período de incubação, foi contado o número de colônias microbianas.

Para o crescimento de bactérias, o meio de cultura utilizado foi o Thorton, e para os fungos, o meio de Martin.

As amostras de solo, para a determinação química, foram colocadas para secar ao ar e depois de peneiradas em malhas de $2 \mathrm{~mm}$ foram realizadas as determinações de $\mathrm{pH}$, matéria orgânica, fósforo, cálcio, magnésio, potássio, alumínio + hidrogênio, capacidade de troca de cátions (T) e saturação por bases (V\%), conforme a metodologia descrita por Raij et al. (1987). 
Todas as determinações foram feitas em quadriplicatas e os resultados expressos com base no solo seco. Os dados foram submetidos à análise da variância e feitas comparações das médias pelo Teste de Tukey a 5\%.

\section{RESULTADOS E DISCUSSÃO}

\subsection{Caracterização química do solo}

Quanto às alterações nas características químicas do solo, proporcionadas pela incorporação de doses de composto de lodo, observa-se, na Tabela 2, que o pH, matéria orgânica, capacidade de troca de cátions, saturação por bases e os teores de fósforo, potássio e cálcio aumentam e que o alumínio + hidrogênio diminuem significativamente no solo, após a adição do composto de lodo. Esses resultados confirmam a observação de outros autores de que a prática de incorporação de composto orgânico resulta na elevação do $\mathrm{pH}$, nos aumentos dos valores da matéria orgânica, fósforo, potássio, cálcio, magnésio, na capacidade de troca de cátions (T), na saturação de bases (V\%) e redução do hidrogênio + alumínio no solo (Silva et al., 2001; Melo et al., 2001; Oliveira et al., 2002; Rocha et al., 2004; Viera et al., 2011).

Tabela 2. Composição química do solo 30 dias após a adição do composto de lodo de esgoto.

\begin{tabular}{c|ccccccccc}
\hline Doses do composto & $\mathbf{p H}$ & $\mathbf{M . O}$ & $\mathbf{P}$ & $\mathbf{K}$ & $\mathbf{C a}$ & $\mathbf{M g}$ & $\mathbf{H}+\mathbf{A L}$ & $\mathbf{T}$ & $\mathbf{V}$ \\
\hline$\left(\mathrm{Mg} \mathrm{ha}^{-1}\right)$ & $\left(\mathrm{CaCl}_{2}\right)$ & $\left(\mathrm{g} \mathrm{dm}^{-3}\right)$ & $\left(\mathrm{mg} \mathrm{dm}^{-3}\right)$ & $-------------\left(\mathrm{mmol}_{\mathrm{c}} \mathrm{dm}^{-3}\right)--------$ & & $(\%)$ \\
0 & $4,2 \mathrm{~d}^{(1)}$ & $23 \mathrm{c}$ & $4 \mathrm{e}$ & $1,5 \mathrm{c}$ & $3,2 \mathrm{c}$ & $1,1 \mathrm{~b}$ & $30 \mathrm{a}$ & $35,8 \mathrm{~b}$ & $16,2 \mathrm{~d}$ \\
20 & $4,7 \mathrm{c}$ & $29 \mathrm{c}$ & $52 \mathrm{~d}$ & $2,7 \mathrm{~b}$ & $20,5 \mathrm{~b}$ & $1,4 \mathrm{~b}$ & $22 \mathrm{~b}$ & $46,6 \mathrm{a}$ & $52,7 \mathrm{c}$ \\
40 & $5,4 \mathrm{~b}$ & $35 \mathrm{~b}$ & $70 \mathrm{c}$ & $3,4 \mathrm{~b}$ & $24,2 \mathrm{~b}$ & $1,6 \mathrm{~b}$ & $18 \mathrm{~b}$ & $47,2 \mathrm{a}$ & $61,8 \mathrm{bc}$ \\
60 & $5,6 \mathrm{~b}$ & $36 \mathrm{~b}$ & $115 \mathrm{~b}$ & $3,9 \mathrm{a}$ & $25,6 \mathrm{~b}$ & $2,1 \mathrm{a}$ & $15 \mathrm{bc}$ & $46,6 \mathrm{a}$ & $67,8 \mathrm{~b}$ \\
80 & $6,4 \mathrm{a}$ & $38 \mathrm{a}$ & $210 \mathrm{a}$ & $4,1 \mathrm{a}$ & $31,5 \mathrm{a}$ & $2,0 \mathrm{a}$ & $11 \mathrm{c}$ & $48,6 \mathrm{a}$ & $77,3 \mathrm{a}$ \\
\hline
\end{tabular}

${ }^{(\mathbf{1})}$ Médias seguidas por letras iguais, não diferem entre si, pelo teste de Tukey a 5\%.

\subsection{Liberação de $\mathrm{CO}_{2}$ no solo}

A Figura 1 apresenta a variação da emissão de $\mathrm{C}-\mathrm{CO}_{2}$ do solo em amostras coletadas ao $0^{\circ}, 7^{\circ}, 14^{\circ}$ e $28^{\circ}$ dias após a incorporação de doses $\left(0,20,40,60\right.$ e $\left.80 \mathrm{Mg} \mathrm{ha}^{-1}\right)$ de composto de lodo de esgoto no solo. Verifica-se que a liberação de $\mathrm{C}-\mathrm{CO}_{2}$, no $1^{\circ}$ dia, mantém-se estável entre os tratamentos e, depois do $7^{\circ}$ dia, com exceção da parcela com $20 \mathrm{Mg} \mathrm{ha}^{-1}$ de composto, a quantidade de C-CO $\mathrm{CO}_{2}$ apresenta uma elevação a partir da dose $40 \mathrm{Mg}$ ha $^{-1}$ até a dose de $80 \mathrm{Mg} \mathrm{ha}^{-1}$ de composto. Para o comportamento, observado na liberação de $\mathrm{C}-\mathrm{CO}_{2}$, entre o $0^{\circ}$ e $7^{\circ}$ dia, pode-se aventar duas hipóteses: na primeira, a causa seria a mudança no substrato energético, ou seja, a maioria dos microrganismos estabelecidos no solo não estava adaptada a decompor compostos orgânicos de baixa relação $\mathrm{C} / \mathrm{N}$ fornecidos pelo composto. A segunda está relacionada às alterações das condições do meio, proporcionadas pela liberação de nutrientes no solo. Esses fatores exigiram dos microrganismos um determinado tempo para adaptação das enzimas e ajustamento do metabolismo das células microbianas ao novo substrato orgânico e à nova condição química do solo (Cattelan e Vitor, 1990; Fortes Neto, 2000; Bettiol e Fernandes, 2004).

Já entre o $7^{\circ}$ e $28^{\circ}$ dia, verifica-se que a dose de $20 \mathrm{Mg} \mathrm{ha}^{-1}$ de composto não forneceu quantidades de substrato energético e nutrientes em proporções para ocasionar alterações significativas na atividade microbiana do solo. Por outro lado, observa-se, na Figura 1, que a produção de $\mathrm{C}_{-} \mathrm{CO}_{2}$ aumenta significativamente com as doses de 40 , 60 e $80 \mathrm{Mg} \mathrm{ha}^{-1}$ de composto. Esse aumento gradativo na quantidade de carbono respirado pela comunidade microbiana no solo com a incorporação de 40, 60 e $80 \mathrm{Mg} \mathrm{ha}^{-1}$ ocorreu, provavelmente, 
porque os microrganismos, após se adaptarem à nova condição do meio, proporcionada pela incorporação do composto, foram estimulados pela elevação do $\mathrm{pH}$, pelos aumentos nos teores de bases trocáveis, fósforo, nitrogênio e principalmente, pelo fornecimento de carbono orgânico (Sullivan et al., 2006; Paula et al., 2010; Zhong et al., 2010). Essa tendência fica mais evidente quando comparamos os valores de $\mathrm{C}-\mathrm{CO}_{2}$ com os resultados da composição química do solo das parcelas com 40, 60 e $80 \mathrm{Mg} \mathrm{ha}^{-1}$ de composto. A esse respeito, diversos autores também verificaram que a emissão de $\mathrm{C}-\mathrm{CO}_{2}$ apresenta uma estreita relação com as alterações químicas do solo (Araújo e Monteiro, 2006; Silva et al., 2007; Santos et al., 2011).

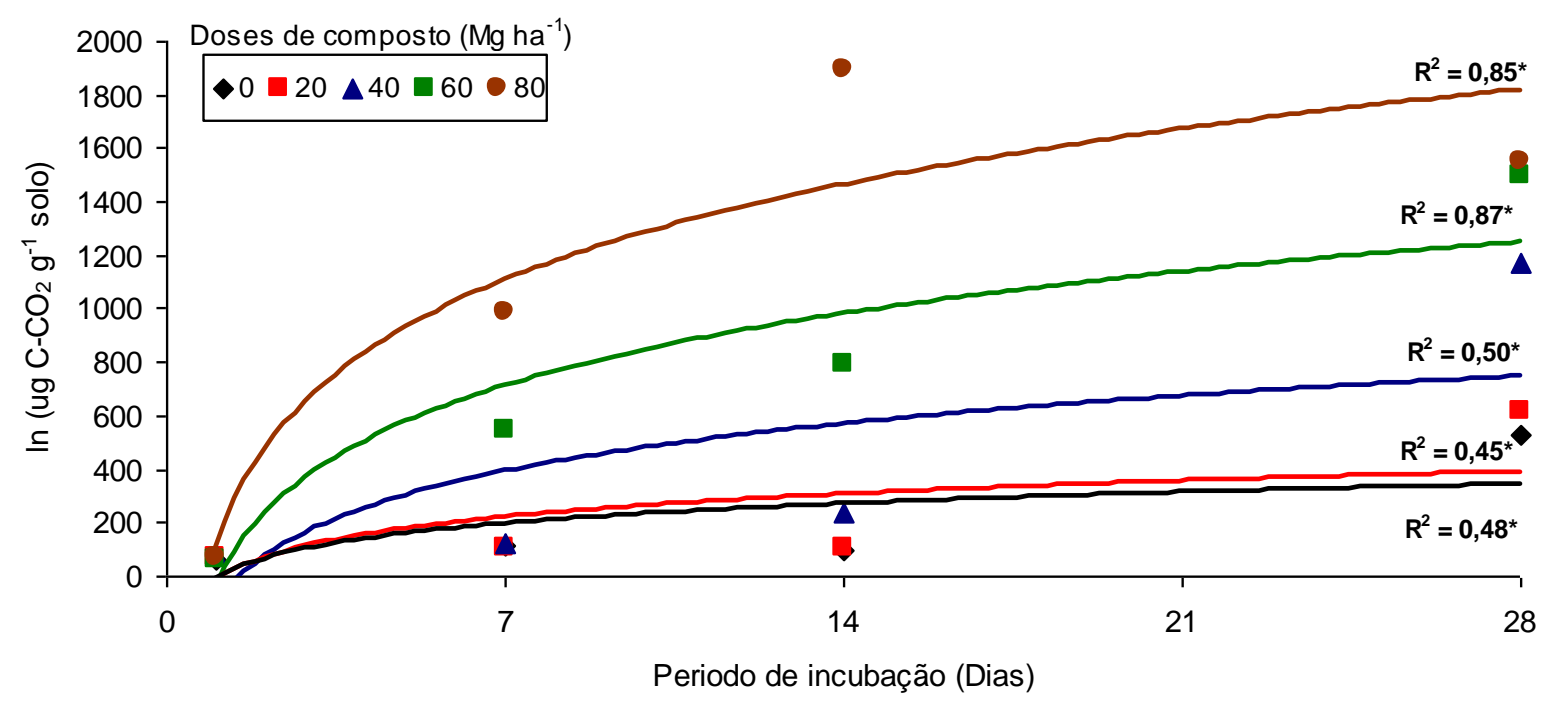

Figura 1. Variação da liberação do C- $\mathrm{CO}_{2}$ do solo incubado com doses de $0,20,40$, 60 e $80 \mathrm{Mg}$ $\mathrm{ha}^{-1}$ de composto de lodo de esgoto.

*significativo a $5 \%$.

A taxa acumulada da atividade respiratória dos microrganismos do solo foi expressa como $\mu \mathrm{g}$ de $\mathrm{C}-\mathrm{CO}_{2}$ liberado por grama de solo, 28 dias após a incorporação das doses de composto de lodo no solo (Figura 2). Os valores variaram significativamente com as doses aplicadas ao solo. Os valores de $\mathrm{C}-\mathrm{CO}_{2}$ acumulados variaram de $800 \mu \mathrm{g} \mathrm{g}^{-1}$ solo para a dose $0 \mathrm{Mg} \mathrm{ha}^{-1}$ a $4.500 \mu \mathrm{g} \mathrm{g}^{-1}$ para a dose de $80 \mathrm{Mg} \mathrm{ha}^{-1}$. Observa-se que os menores valores de C$\mathrm{CO}_{2}$ foram determinados nas parcelas com 0 e $20 \mathrm{Mg} \mathrm{ha}^{-1}$ de composto, e que os maiores valores nas amostras de solo foram provenientes das parcelas com 40, 60 e $80 \mathrm{Mg} \mathrm{ha}^{-1} \mathrm{de}$ composto. Isto ocorreu devido à maior atividade biológica que, por sua vez, foi estimulada pela quantidade de carbono orgânico proporcionada pelo aumento das doses do composto (Balota et al., 1998).

Analisando em conjunto os resultados das Figuras 2, 3 e 4, observa-se que a taxa acumulada de $\mathrm{C}-\mathrm{CO}_{2}$ liberado do solo reflete claramente o consumo de carbono orgânico pela comunidade de bactérias e fungos que se estabeleceram no solo com a aplicação de 40, 60 e $80 \mathrm{Mg} \mathrm{ha}^{-1}$ de composto de lodo de esgoto. Segundo Jahnel et al. (1999), esse fato ocorre devido ao crescimento de espécies microbianas tolerantes às mudanças proporcionadas pela incorporação do composto no solo. Também não se pode esquecer de que, juntamente com o composto, foi incorporado um grande número de células microbianas que não estava presente no solo (Fortes Neto, 2000). Deve-se ressaltar que, nesse caso, a alta taxa de $\mathrm{C}-\mathrm{CO}_{2}$ observada no solo com composto é considerada uma característica desejável porque, com a decomposição do composto, são liberados nutrientes para as plantas (Roscoe et al., 2006). 


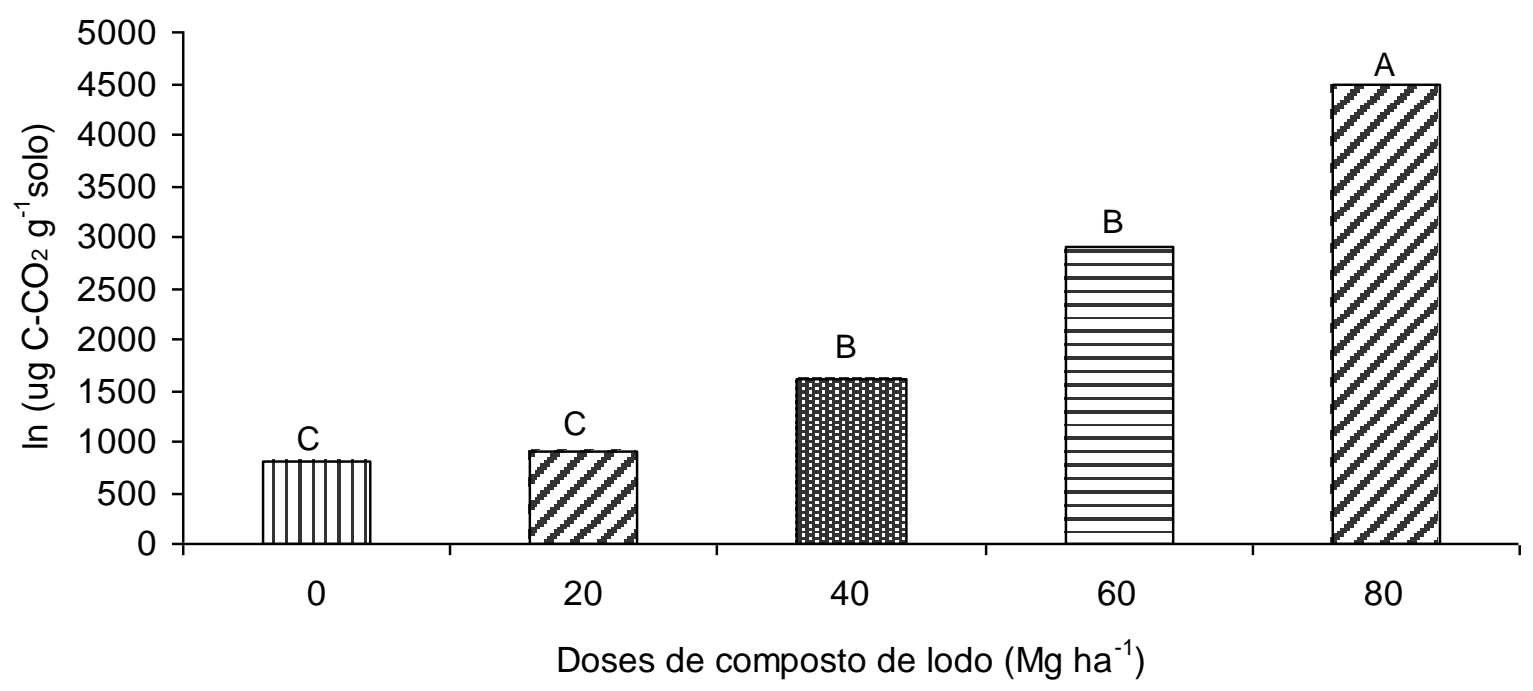

Figura 2. Taxa acumulada de $\mathrm{CO}_{2}$ liberado de amostras de solo coletadas nas parcelas com doses de $0,20,40,60$ e $80 \mathrm{Mg} \mathrm{ha}^{-1}$ de composto de lodo de esgoto.

Nota: Médias seguidas por letras maiúsculas iguais, não diferem entre si, pelo teste de Tukey a 5\%).

\subsection{Número de bactérias no solo}

A contagem do número mais provável (NMP) de bactérias, realizada 30 dias após a incorporação das doses de composto de lodo de esgoto, apresentou diferenças significativas entre os tratamentos, e os valores variaram entre 0,70 a 51,30 × $10^{5}$ por grama de solo (Figura $3)$. Esses resultados, quando comparados com os valores verificados em áreas com cultivos agrícolas, estão relativamente baixos, pois Silva Filho e Vidor (1984) e Catellan e Vidor (1990) constaram valores variando entre $10^{6}$ a $10^{7}$. No entanto, o número de bactérias determinado no presente estudo é similar aos valores observados nas pesquisas com aplicação de composto orgânico e lodo de esgoto (Fortes Neto, 2000; Bettiol e Fernandes, 2004).

Ainda na Figura 3, observa-se que o tratamento sem a adição do composto apresentou os menores números de bactérias. Por outro lado, nas parcelas com aplicação de doses de composto, constatou-se um aumento em consonância com o aumento da dose de composto. Esses aumentos na contagem de bactérias, verificados nos solos com a incorporação de composto, podem ter ocorrido devido à inoculação no solo de bactérias existentes no composto e, também, pelo fornecimento de substratos energéticos e nutrientes provenientes da decomposição do composto no solo, favorecendo, dessa maneira, a multiplicação das células bacterianas (Jahnel et al., 1999; Leite, 2009).

$\mathrm{Na}$ avaliação em conjunto dos resultados da composição química do solo (Tabela 2) e do número de bactérias (Figura 3), verifica-se que a comunidade de bactérias refletiu nas alterações ocasionadas pela liberação de nutrientes devido à decomposição do composto no solo. Provavelmente, o fósforo e o cálcio devem ter sido muito importantes para o aumento no número de bactérias no solo, pois os teores de fósforo e cálcio apresentaram aumentos significativos com a elevação na dose de composto incorporada no solo. Outro fator que pode ter contribuído para esse comportamento foi a elevação no $\mathrm{pH}$ do solo, que variou de 4,2 sem a adição de composto para 6,4 na parcela com $80 \mathrm{Mg} \mathrm{ha}^{-1}$ de composto. Essas condições do $\mathrm{pH}$, próximas da neutralidade favorecem o crescimento das células bacterianas que tendem a predominar no solo devido à redução da acidez e neutralização do alumínio. Esses resultados confirmam as observações de outros autores de que a melhoria na fertilidade do solo estimula o desenvolvimento das bactérias no solo (Mafra et al., 1998; Jahnel et al., 1999). 


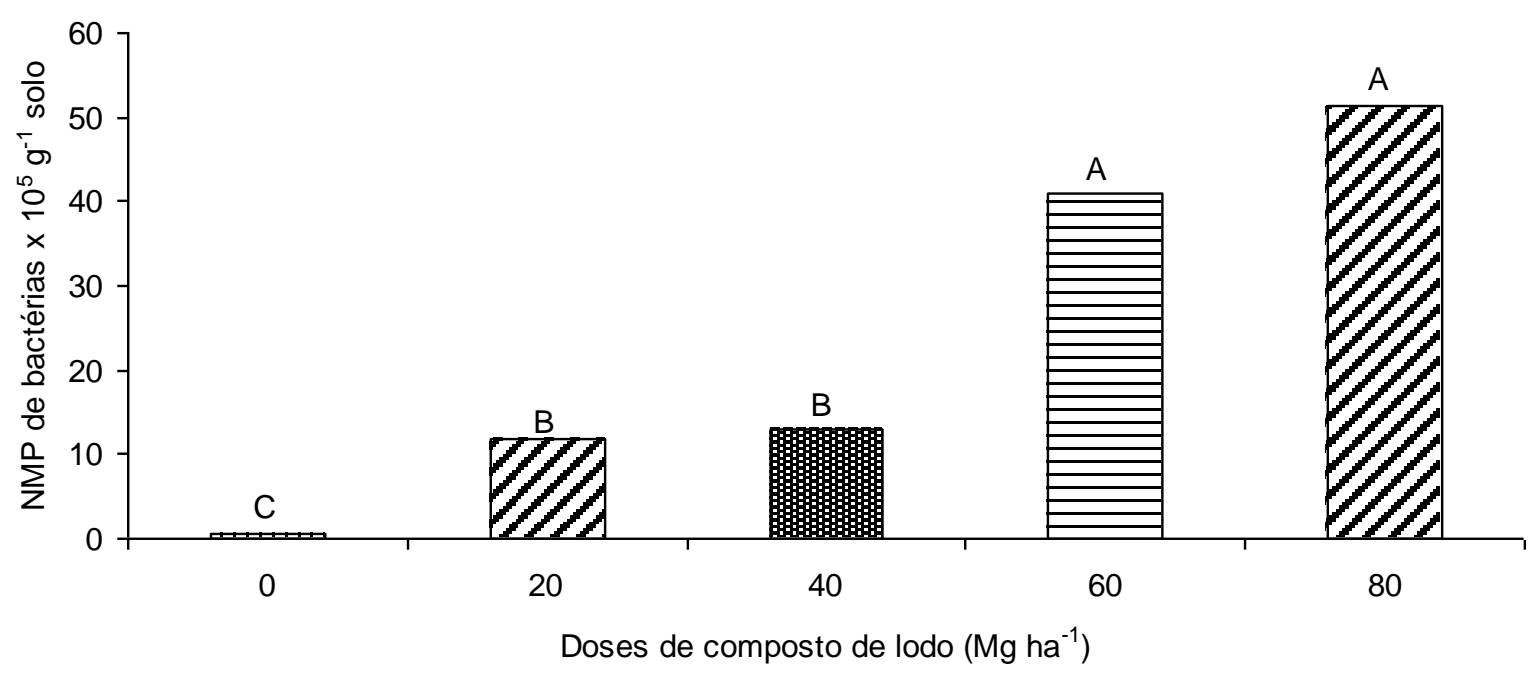

Figura 3. Número Mais Provável de bactérias $x 10^{5} \mathrm{~g}^{-1}$ de solo determinado na camada de $0-10$ $\mathrm{cm}$ de profundidade de solo tratado com doses de $0,10,20,30$ e $40 \mathrm{Mg} \mathrm{ha}^{-1}$ de composto de lodo de esgoto.

Nota: Médias seguidas por letras maiúsculas iguais, não diferem entre si, pelo teste de Tukey a 5\%).

Convêm destacar que o aumento no número de bactérias observado no presente estudo reflete o desenvolvimento de células bacterianas que foram estimuladas pela aplicação do composto no solo, ou seja, pela metodologia utilizada não é possível verificar se houve também aumento na diversidade de espécies bacteriana no solo. A esse respeito, Banerjee et al. (1997) constataram que a incorporação de lodo de esgoto reduziu a diversidade de espécie microbiana no solo, porém, para as espécies que permaneceram, o lodo não teve efeito negativo e até favoreceu o crescimento dos microrganismos.

\subsection{Número de fungos no solo}

O número mais provável (NMP) de fungos por grama de solo apresentou variação significativa entre os tratamentos (Figura 4). Observa-se que a comunidade de fungos aumenta no solo na medida em que se elevam as doses de composto incorporado ao solo, nota-se que os valores variaram entre $0,2 \mathrm{NMP} \times 10^{4} \mathrm{~g}^{-1}$ solo no tratamento sem composto a 4,8 NMP x $10^{4} \mathrm{~g}^{-1}$ solo no tratamento com $80 \mathrm{Mg} \mathrm{ha}^{-1}$ de composto. Esses valores estão no limite abaixo dos comumente encontrados para os fungos em áreas de solo com cultivos agrícolas, que variam entre $10^{4}$ a $10^{6}$, porém acima do limite de $10^{3}$ constatado em solos com adição de fertilizantes orgânicos produzidos a partir de resíduos urbanos e agroindustriais (Cattelan e Vidor, 1990; Jahnel et al., 1999; Bettiol e Fernandes, 2004; Silva Júnior e Pereira, 2007).

O aumento no número de fungos observado no solo com a adição de 20, 40, 60 e $80 \mathrm{Mg} \mathrm{ha}^{-1}$ de composto foi similar ao ocorrido com as bactérias (Figura 3). Isto ocorreu devido ao fornecimento de carbono orgânico e à disponibilidade de nutrientes liberados pela decomposição do composto, pois, no solo sem composto, foi determinado o menor valor no número de fungos (Jahnel et al., 1999; Marschner et al., 2003; Zhong et al., 2010).

A elevação no número de fungos pode estar relacionada ao crescimento de espécies adaptadas a composição química e física do composto, em outras palavras, o composto pode ter proporcionado um efeito seletivo sobre as espécies de fungos no solo (Silva et al., 2007). Estudos realizados por Leite (2009) constataram que a aplicação de lodo de esgoto reduziu a diversidade de espécies de fungos no solo e favoreceu o predomínio de colônias pertencentes aos gêneros Aspergillus sp e Penicillium SP, quando comparado com o solo sem aplicação de lodo. 


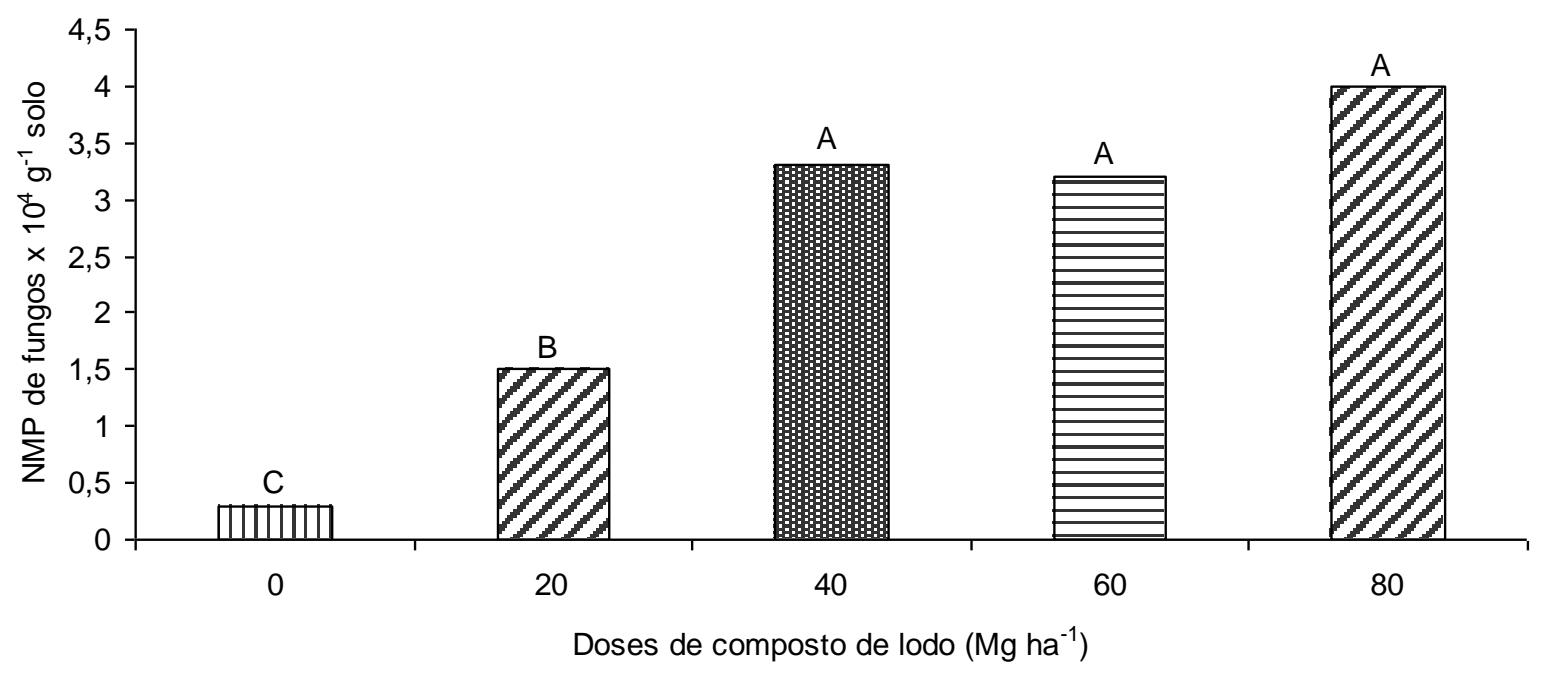

Figura 4. Unidade formadora de colônias de fungos $\mathrm{x} 10^{4} \mathrm{~g}^{-1}$ de solo determinadas na camada de 0-10 cm de profundidade de solo tratado com doses de 0,10, 20, 30 e $40 \mathrm{Mg} \mathrm{ha}^{-1}$ de composto de lodo de esgoto.

Nota: Médias: seguidas por letras maiúsculas iguais, não diferem entre si, pelo teste de Tukey a 5\%).

Analisando os resultados da Figura 4 e Tabela 2, constata-se que o crescimento da comunidade de fungos, assim como a de bactéria (Figura 3), foi também estimulado pela decomposição da matéria orgânica e a melhoria na fertilidade do solo proporcionada pela incorporação do composto de lodo de esgoto. A este respeito vários estudos têm verificado que as comunidades microbianas do solo tratado com resíduos orgânicos apresentam relação direta com a decomposição e liberação de nutrientes no solo (Fortes Neto, 2000; Marschner et al., 2003; Sullivan et al., 2006; Zhong et al., 2010).

\section{CONCLUSÃO}

A atividade microbiana do solo, medida pela liberação de $\mathrm{CO}_{2}$, e a contagem de bactérias e fungos foram sensíveis à incorporação das doses do composto de lodo.

$\mathrm{O}$ aumento no número de bactérias e fungos foi proporcional a elevação da liberação do $\mathrm{CO}_{2}$ no solo.

A adição do composto forneceu substrato energético e nutriente para os microrganismos do solo.

A medida de liberação de $\mathrm{CO}_{2}$ indicou que doses do composto acima de $20 \mathrm{Mg} \mathrm{ha}^{-1}$ ocasionou impactos significativos sobre a atividade microbiana do solo.

O composto de lodo de esgoto testado pode ser aplicado até a dose de $20 \mathrm{Mg} \mathrm{ha}^{-1}$.

\section{AGRADECIMENTOS}

Agradecemos à FIBRIA Celulose S/A pelo acesso à área de estudo ao CNPq por ter concedido uma bolsa de iniciação científica para a aluna Ericléia Bürg Suszek e a Profa. M.Sc. Ângela Popovici Berbare do Departamento de Ciências e Letras da Universidade de Taubaté. 


\section{REFERÊNCIAS}

ARAÚJO, A. S. F.; MONTEIRO, R. T. R. Microbial biomass and activity in a Brazilian soil amended with untreated and composted textile sludge. Chemosphere, Oxford, v. 64, n. 6, p. 1043-1046, 2006. http://dx.doi.org/10.1016/j.chemosphere.2006.01.040

BALOTA, E. L.; COLOZZI-FILHO, A.; ANDRADE, D. S.; HUNGRIA, M. Biomassa microbiana sua atividade em solos sob diferentes sistemas de preparo e sucessão de culturas. Revista Brasileira de Ciência do Solo, Campinas, v. 22, n. 4, p. 641-649, 1998.

BANERJEE, M. R.; BURTON, D. L.; DEPOE, S. Impact of sewage sludge application on soil biological characteristics. Agriculture, Ecosystems \& Enviroment, Oxford, v. 66, n. 3, p. 241-249. 1997. http://dx.doi.org/10.1016/S0167-8809(97)00129-1

BETTIOL,W.; FERNANDES, S. A. P. Efeito do lodo de esgoto na comunidade microbiana e atributos químicos do solo. Jaguariúna: Embrapa Meio Ambiente, 2004. (Comunicado Técnico).

BRASIL. Conselho Nacional do Meio Ambiente. Resolução CONAMA n 375/2006. Define critérios e procedimentos, para o uso agrícola de lodos de esgoto gerados em estações de tratamento de esgoto sanitário e seus produtos derivados, e dá outras providências. Disponível em: <http://www.mma.gov.br/CONAMA>. Acesso em: 12 jun 2012.

BROOKES, P. C. The use of microbial parameters in monitoring soil pollution by heavy metals. Biology and Fertility of Soils, Firenze, v, 19, n. 4, p. 269-279, 1995. http://dx.doi.org/10.1007/BF00336094

CATELLAN, A. J.; VIDOR, C. R. Flutuação da biomassa, atividade e população microbiana do solo. Revista Brasileira de Ciência do Solo, Viçosa, MG, v. 14, p. 133-142, 1990.

DICK, R. P. Soil enzyme assays as indicators of soil quality. In: DORAN, J. W. L.; COLEMAN, D. C.; BEZDICEK, D. F.; STEWART, B. A. (Eds.). Defining soil quality for a sustainable enviroment. Madison: Soil Science Society of America, 1994. p. 107-124.

DORAN, J. W; PARKINSON, T. B. Defining and assessing soil quality. In: DORAN, J. W. L.; COLEMAN, D. C.; BEZDICEK, D. F.; STEWART, B. A. (Eds.). Defining soil quality for a sustainable environment. Madison: Soil Science Society of America, 1994. p. 3-22.

EMPRESA BRASILEIRA DE PESQUISA AGROPECUÁRIA - EMBRAPA. Sistema brasileiro de classificação de solos. Brasília: Embrapa, 1999. 412p.

ELSAS, J. D. VAN; TREVORS, J. T.; WELLINGTON, E. M. H. Modern soil microbiology. New York: Marcel Dekker, 1997. 682p.

FORTES NETO, P. Degradação de biossólido incorporado ao solo avaliada através de medidas microbiológicas. 2000. 113f. Tese (Doutorado) - Escola Superior de Agricultura “Luiz de Queiroz", Universidade de São Paulo, Piracicaba, 2000.

GIL-SOTRES, F.; TRASAR-CEPEDA, C.; LEIRÓS, M. C.; SEOANE, S. Different approaches to evaluating soil quality using biochemical properties. Soil Biology and Biochemistry, Oxford, v. 37, n. 5, p. 877-887, 2005. http://dx.doi.org/10.1016/j.soilbio. 2004.10.003 
ILHENFELD, R. G. K.; ANDREOLI, C. V. Uso de lodo em áreas de produção. In: COMPANHIA DE SANEAMENTO DO PARANÁ; PROGRAMA DE PESQUISA EM SANEAMENTO BÁSICO. Uso e manejo do lodo de esgoto na agricultura. Curitiba, 1999. p. 62-73. Disponível em: <http://www.finep.gov.br/prosab/livros/ uso_ manejo_lodo_agricultura.pdf $>$. Acesso em: 17 ago. 2012.

JAHNEL, M. C.; CARDOSO, E. J. B. N.; DIAS, C. T. S. Determinação do número mais provável de microrganismos do solo pelo método de plaqueamento por gotas. Revista Brasileira de Ciência do Solo, Viçosa, MG, v. 23, n. 3, p. 553-559, 1999.

LEITE, M. V. Fungos filamentosos do lodo de esgoto: impacto na microbiota fúngica e potencial enzimático. 2009. 65f. Dissertação (Mestrado em Desenvolvimento de Processos Ambientais) - Universidade Católica de Pernambuco, Recife, 2009.

LISBOA, B. B.; VARGAS, L. K.; SILVEIRA, A. O.; MARTINS, A. F.; SELBACH, P. A. Indicadores microbianos de qualidade do solo em diferentes sistemas de manejo. Revista Brasileira de Ciência do Solo, Viçosa, MG, v. 36, n. 1, p. 45-55, 2012. http://dx.doi.org/10.1590/S0100-06832012000100004

MAFRA, A. L.; MIKLÓS, A. A. W.; VOCURCA, H. L.; HARKALY, A. H.; MENDOZA, E. Produção de fitomassa e atributos químicos do solo sob cultivo em aléias e sob vegetação nativa de cerrado. Revista Brasileira de Ciência do Solo, Viçosa, MG, v. 22, n. 1, p. 43-48, 1998.

MARCHIORI JÚNIOR, M.; MELO, W. J. Carbono da biomassa microbiana e atividade enzimática de um solo sob mata natural, pastagem e cultura do algodoeiro. Revista Brasileira de Ciência do Solo, Viçosa, MG, v. 23, n. 2, p. 257-263, 1999.

MARSCHNER, P.; KANDELER, E.; MARSCHNER, B. Structure and function of the soil microbial community in a long-term fertilizer experiment. Soil Biology and Biochemistry, Oxford, v. 35, n. 3, p. 453, 2003. http://dx.doi.org/10.1016/S00380717(02)00297-3

MELO, W. J. DE; MARQUES, O. M.; MELO, V. P. O uso agrí́cola do biossólido e as propriedades do solo. In: TSUTIYA, M. T.; COMPARINI, J. B.; ALEM SOBRINHO, P.; HESPANHOL, I. et al. (Eds.). Biossólidos na agricultura. São Paulo: SABESP, 2001. p. 289-363.

OLIVEIRA, F. C.; MATIAZZO, M. E.; MARCIANO, C. R.; ROSSETO, R. Efeitos de aplicações sucessivas de lodo de esgoto em Latossolo Amarelo distrófico cultivado com cana-de-açucar: carbono orgânico, condutividade elétrica, pH e CTC. Revista Brasileira de Ciência do Solo, Viçosa, MG, v. 26, n. 2, p. 505-519, 2002.

PAULA, A. M.; FONSECA, A. F.; CARDOSO, E. J. B. N.; MELFI, A. J. Microbial metabolic potential affected by surplus wastewater irrigation in tropical soil cultivated with Tifton 85 bermuda grass (Cynodon dactylon Pers. X. C. niemfuensis Vanderyst). Water, Air \& Soil Pollution, Oxford, v. 205, n. 1/4, p. 161-171, 2010. http://dx.doi.org/10.1007/s11270-009-0063-3

RAIJ, B. van; QUAGGIO, J. A; CANTARELLA, H. et al. Análise química do solo para fins de fertilidade. Campinas: Fundação Cargill, 1987. 170p. 
ROCHA, G. N.; GONÇALVES, J. L. M.; MOURA, I. M. Mudanças da fertilidade do solo e crescimento de um povoamento de Eucaliptus grandis fertilizado com biossólido. Revista Brasileira de Ciência do Solo, Viçosa, MG, v. 28, n. 4, p. 623-639, 2004. http://dx.doi.org/10.1590/S0100-06832004000400005

ROSCOE, R.; MERCANTE, F. M.; MENDES, I. C.; REIS JR., F. B.; SANTOS, J. C. F.; HUNGRIA, M. Biomassa microbiana do solo: fração mais ativa da matéria orgânica. In: ROSCOE, R.; MERCANTE, F. M.; SALTON, J. C. Dinâmica da matéria orgânica do solo em sistemas conservacionistas: modelagem matemática e métodos auxiliares. Dourados: Embrapa Agropecuária Oeste, 2006. p. 163-198.

SANTOS, J. A.; NUNES, L. A. P. L.; MELO, W. J.; ARAÚJO, A. S. F. Tannery sludge compost amendment rates on soil microbial biomass in two different soils. European Journal of Soil Biology, Braunschweig, v. 47, n. 2, p. 146-151, 2011. http://dx.doi.org/10.1016/j.ejsobi.2011.01.002

SIlVA, F. C.; BOARETto, A. E.; BERTON, R. S.; ZOTElli, H. B.; PEXE, C. A.; BERNARDES, E. M. Efeito de lodo de esgoto na fertilidade de um Argissolo Vermelho-Amarelo cultivado com cana-de-açúcar. Pesquisa Agropecuária Brasileira, Brasília, DF, v. 36, n. 5, p. 831-840, maio 2001. http://dx.doi.org/10.1590/S0100204X2001000500014

SILVA FILHO, G. N.; VIDOR, C. R. As práticas de manejo de solo na população microbiana. Revista Brasileira de Ciência do Solo, Viçosa, MG, v. 8, p. 291-296, 1984.

SILVA, E. E. da; AZEVEDO, P. H. S. de; DE-POLI, H. Determinação da respiração basal (RBS) e quociente metabólico do solo $\left(\mathbf{q} \mathbf{C O}_{2}\right)$. Seropédica: Embrapa Agrobiologia, 2007. 4p. (Comunicado Técnico, 99).

SILVA JÚNIOR, F. M. R.; PEREIRA, S. V. Ecologia e fisiologia de fungos filamentosos isolados de solo contaminado por metais pesados. Revista Brasileira de Biociências, Porto Alegre, v. 5, supl. 2, p. 903-905, 2007.

SUlliVAN, T. S.; STROMBERGER, M. E.; PASCHKE, M. W. , IPPOLITO, J. A. Longterm impacts of infrequent biosolids applications on chemical and microbial properties of a semi-arid rangeland soil. Biology and Fertility of Soils, Firenze, v. 42, n. 3, p. 258-266, 2006. http://dx.doi.org/10.1007/s00374-005-0023-z

STOTZKY, G. Microbial respiration. In: BLACK, C. A.; EVANS, D. D.; WHITE, J. L.; ENSMINGER, L. E.; CLARK, F. E. (Eds.). Methods of soil analysis. Madison: American Society Agronomy, 1965. p 1550-1570.

TRASAR-CEPEDA, C.; LEIRÓS, M. C.; SEONE, S.; GIL-SOTRES, F. Limitations of soil enzymes as indicators of soil pollution. Soil Biology and Biochemistry, Oxford, v. 32, n. 13, p. 1867-1875, 2000. http://dx.doi.org/10.1016/S0038-0717(00)00160-7

TURCO, F. R.; KENNEDY, A. C.; JAWSON, M. D. Microbial indicators of soil quality. In: DORAN, J. W. L.; COLEMAN, D. C.; BEZDICEK, D. F.; STEWART, B. A. (Eds.). Defining soil quality for a sustainable enviroment. Madison: Soil Science Society of America, 1994. p. 73-90. (Special Publication, n. 35). 
SUSZEK, E. B.; FORTES NETO, P.; FORTES, N. L. P.; SILVA, E. M. A. M.; BRAMBATTI, F.; SILVA, C. R; PATROCINIO, D. D. Atributos microbianos do solo fertilizado com composto de lodo de esgoto Ambi-Agua, Taubaté, v. 7, n. 2, p. 49-61, 2012. (http://dx.doi.org/10.4136/ambi-agua.915).

VIEIRA, G. A.; CASTILHOS, D. D.; CASTILHOS, R. M. V. Atributos do solo e crescimento do milho decorrentes da adição de lodo anaeróbio da estação de tratamento de efluentes da parboilização do arroz. Revista Brasileira de Ciência do Solo, Viçosa, MG, v. 35, n. 2, p. 535-542, 2011. http://dx.doi.org/10.1590/S010006832011000200022

ZHONG, W.; GU, T.; WANG, W.; ZHANG, B.; LIN, X.; HUANG, Q.; SHEN, W. The effects of mineral fertilizer and organic manure on soil microbial community and diversity. Plant and Soil, Dordrecht, v. 326, n. 1/2, p. 511-522, 2010. http://dx.doi.org/10.1007/s11104-009-9988-y 